\title{
New directions for Brazilian Medical Residency
}

\author{
Luis Yu
}

$\mathrm{M}^{\mathrm{c}}$ edical residency (MR) is considered the best way of medical training and specialization. A long and successful trajectory has been settled since its inauguration at Hospital das Clínicas da Faculdade de Medicina da Universidade de São Paulo (HCFMUSP) and Hospital dos Servidores do Rio de Janeiro in 1944.

At that time, trainees worked full time in the hospital. They had general practice in the first 2 years and were allowed to specialize after this initial training. In 1954, Dr. Cantidio de Moura Campos, clinical director, changed the medical training, introducing two trainees categories: interns and residents. Interns were trained in basic areas for 1 year while residents were trainned in specialized services for up to 3 years. In 1959, training was open to external medical students. Medical residency was offered in 4 main areas: Internal Medicine, Surgery, Gynecology/Obstetrics and Pediatrics. In 1973, internship was extended for 2 years $\left(5^{\text {th }}\right.$ and $6^{\text {th }}$ medical year) and medical residency for 3 years, where $80 \%$ of positions were offered to FMUSP undergraduates and $20 \%$ to external medical students.

In 1977, president Ernesto Geisel promulgated the Decree-law n ${ }^{\circ} 80281 / 77$, establishing the Comissão Nacional de Residência Médica (CNRM), a colegiate with equal members from government and medical societies, that is responsible for the regulation, accreditation and evaluation of medical residency programs. Few years later, in 1981, president João Figueiredo enacted the Law $\mathrm{n}^{\circ}$ 6932/81 that established MR as a post-graduate course for medical students, in which specialization occurs under service training in Health institutes, academic or not, under supervision of highly ethical and professional qualified doctors, and also, established several important regulations such as working load, schoolarship and social security benefits.

Thereafter, several MR programs were accredited in the entire country, especially in southeastern and southern states. However, because of the large number of medical schools inaugurations in the last decades, a large quantity of medical students have graduated without corresponding MR positions. Currently, it is estimated a 30\% deficit between medical graduates and residency positions. Additionally, several available MR positions are not fullfilled because of either the specialties are not sought or the MR programs are considered deficient. This problem also affects the state of Sao Paulo, where some of the best MR programs are offered, several positions remain open because of the lack of candidates to these programs.

In recent years, this long and successful MR pathway has suffered substantial modifications. In september 15, 2011, president Dilma Roussef enacted the Decree-Law $\mathrm{n}^{\circ} 7562 / 11$, introducing modifications in the CNRM composition: inclusion of more representatives

Professor Associado do Department of Clínica Médica da Faculdade de Medicina da Universidade de São Paulo - FMUSP. Vice Coordenador da COREME-FMUSP.

Mailing address: Universidade de São Paulo, Faculdade de Medicina da Universidade de São Paulo. Av. Dr. Arnaldo 455 - $3^{\circ}$ S. 3310 Cerqueira Cesar. 01246-903 - Sao Paulo, SP, Brasil. Email: luisyu@usp.br 
from the government and medical societies and changes in regulation, supervision and evaluation of residency programs.

The Secretary of Superior Education acts as president of the CNRM and has the power of decision in cases of even voting in the plenary. Furthermore, an Appeal Chamber was created which is constituted by 3 members: one representative from Health Ministry (MS), one from Education Ministry (MEC) and one from the Medical Societies. This chamber has the power of revoking, repealing or endorsing the plenary decisions. Because of these modifications, several medical societies refused to participate in the plenary sessions.

Following this act, the federal government published the Interministerial Act MEC/MS n 2087/2011, establishing the Programa de Valorização da Atenção Básica (PROVAB) which intended to promote primary care in remote and most needed areas. Certainly, primary care attention should be prioritized in the country, through the formation and distribution of multiprofessional groups of Family Medicine and improvements in the infrastructure for diagnosis and therapeutics in the entire country. However, in order to estimulate the demand for this program, federal government decided to provide a $10 \%$ bonification in the final grade of medical selection programs for those candidates who have completed and approved in the PROVAB program.

Because of the lack of MR positions, the poor quality of most of MR programs, the need for professional capacitation or specialization and the strong competition for the best programs, certainly this bonification became a sucessful strategy to attract young physicians to the PROVAB. However, several universities and other institutions, especially in Sao Paulo, have strongly opposed to this bonification. FMUSP assumed a position against the bonification but not against the program because it has always valued the merit and competence for admission to the university. Aditionally, this interministerial act can not overcome the constitutional right that grants university independence and autonomy regarding selection criteria and teaching and curriculum guidelines.

The program PROVAB also presents several other flaws and inconsistencies: no equal and universal selection, lack of local supervision, unclear evaluation and approval criteria and, a compatible calendar with the institutions that offer MR programs. Nonetheless, Sao Paulo state universities have provided several suggestions for the program improvement which were entirely rejected by the MEC.

This position of FMUSP against this bonus has been legally fought in the court of law by the federal government. Nevertheless, all law suits have been disputed and temporarily rejected. Unfortunately, several other institutions were also legally sued and have agreed with bonus concession, suffering several distortions in the selection process.

PROVAB was incorporated in the Law $n^{\circ} 12871 / 13$ - Lei dos Mais Médicos - recently enacted by president Dilma Roussef, whose main objectives are: reduce the need for doctors in priority areas designated by SUS, enhance primary care, improve medical formation, estimulate doctors incorporation in SUS, promote the exchange of knowledge and experience between brazilian and foreign physicians, and to teach doctors about public health policies and SUS organization and functioning.

In order to accomplish these objectives, the federal Law establishes: reordering of medical graduation and residency positions, new parameters for medical formation, promotion of primary care in priority areas designated by SUS through integration of learning-service, including international exchange programs.

Medical residency has been successful regarding specialists formation, professional capacitation and teachers and researchers formation. Indeed, the role of MR has become even more relevant currently because of the several and indiscriminate openings of medical schools in the entire country supported by this Law, which will lead to graduation of thousands of unprepared and incompetent doctors. Medical residency is the best teaching instrument that is capable of preparing that massive number of medical graduates, providing them knowledge and adequate professional capability.

The Law $n^{\circ} 12871 / 13$ establishes several other substantial modifications for MR, especially after December 31,2018. This is the deadline for the government to offer equivalent residency positions to all medical graduates. At that time, the program PROVAB will finish because of other actions aimed at promoting primary care 
and provision of equivalent number of MR positions to all graduates. This latter objective is warranted despite of the difficulties to establish good residency programs, especially without the participation of academic institutions, in order to attract and settle medical graduates all over the country. Certainly, funding of these new MR schoolarships and the definition of priority specialties will be some of the major problems in order to establish those goals.

In addition, this Law will change substantially the access to the MR programs after 2018. Most of the programs, except Medical Genetics, Traffic Medicine, Sports Medicine, Physical and Rehabilitation Medicine, Legal Medicine, Nuclear Medicine, Pathology and Radiotherapy, will require 1-2 years of Family and Community Health (FCM) residency before entering other basic area or specialty. This requirement will extend in 1-2 years the medical professional training in Brazil.

It is a matter of debate whether this mandatory requirement (1-2 y FCM) is important for the training of several clinical and surgical specialties, such as: Dermatology, Radiology, Clinical Pathology and
Laboratory, Endoscopy and Plastic Surgery. Additionally, it seems unnecessary for the 3 years specialties, such as Pediatrics, in which primary care is substantially taught during the regular program or for the long duration programs such as Neurosurgery or Cardiovascular surgery (5 y duration). Furthermore, it will very difficult to establish FCM programs for the majority of residents, especially because of the shortness of specialized supervisors and teachers and the lack of appropriate infrastructure and equipments for the FCM teaching and training.

In conclusion, recent enacted Decree-laws and Laws regarding medical graduation and residency will definitely impact Brazilian Medicine and Public Health. There are no doubts about the legitimate rights of applying what is established in the constitution. However, it would be desirable and necessary the participation and discussion with teaching institutions, academic or not, involved in medical graduation and residency in order to adequately and properly elaborate the legal regulation for Brazilian Medicine and Public Health. 